\title{
TENDÊNCIAS TECNOLÓGICAS E DIDÁTICAS NA EDUCAÇÃO A DISTÂNCIA
}

\author{
TIMBÓ SC/SC JULHO/2018
}

\author{
Silvana Sueli de Oliveira Zilse - UNIASSELVI - zilse@flipp.com.br \\ Julia Ropelato Floriani - UNIASSELVI - rjullia@hotmail.com
}

Tipo: Investigação Científica (IC)

Natureza: Relatório Final de Pesquisa

Categoria: Métodos e Tecnologias

Setor Educacional: EDUCAÇÃO SUPERIOR

\begin{abstract}
RESUMO
O presente artigo busca expor as principais tendências tecnológicas e didáticas na modalidade de Educação a Distância, levando-se em consideração os diversos modelos de cursos e o avanço dos recursos que podem ser utilizados para mediar o processo ensino-aprendizagem. Seu maior objetivo é viabilizar as informações mais recentes a respeito do assunto aos profissionais interessados no aprimoramento das práticas pedagógicas na EAD. Para fundamentar este trabalho, foram realizadas pesquisas em artigos e obras científicas sobre o tema, evidenciando as principais características das abordagens em marcha na EAD.
\end{abstract}

Palavras-chave: Tecnologia. Didática. Educação a Distância. 


\section{INTRODUÇÃO}

Em um mundo de nativos digitais, o papel do docente transcende o mero repasse de conhecimentos e o direciona ao desenvolvimento de novas competências, no intuito de torna-lo um mediador de aprendizagem, um apoio ao estudante rumo à autonomia em seus estudos. A promoção da qualidade nesta oferta de ensino permeada pela tecnologia também é um forte componente a ser considerado por profissionais da área, posto que qualquer irregularidade ou falha no processo de elaboração de recursos pedagógicos, pode comprometer o aprendizado de um número muito alto de alunos. A razão para a concepção deste trabalho é que o avanço tecnológico e didático é muito superior à velocidade com que artigos e livros sobre tecnologia e didática em educação a distância são disponibilizados e, por consequência, os que tem relação com as mais novas ferramentas desta modalidade. O principal benefício desta pesquisa é a provisão de informações abrangentes, de utilidade a todos os atores envolvidos na educação a distância no ensino, tais como tutores, coordenadores, professores e gestores, com o objetivo de aperfeiçoar ainda mais os meios pedagógicos e tecnológicos deste modelo de ensino. Esta pesquisa foi conduzida por meio de levantamento bibliográfico em livros, artigos acadêmicos e fontes eletrônicas sobre os principais conceitos relacionados à tecnologia e didática atuais na modalidade de EAD.

\section{TECNOLOGIA E DIDÁTICA NA EDUCAÇÃO A DISTÂNCIA}

A popularização da internet em todos os níveis sociais alterou radicalmente a maneira como o ser humano se comunica, como compra, como trabalha e, principalmente, como estuda. A educação a distância evolui muito rapidamente, pois sua medida de crescimento está atrelada ao avanço da tecnologia e como ela pode ser empregada no ensino. Além disso, a concorrência acirrada entre as organizações que oferecem cursos a distância requer um olhar mais apurado às exigências do estudante. "A aceleração do crescimento da educação, em geral, está tornando cada vez mais indistintos os limites entre disciplinas, instituições e locais geográficos - um mundo cada vez mais complexo, mais veloz nas mudanças e mais pluralista." (LITTO, 2009, p. 14). A reflexão em torno a este tema é comum e gera mais e mais questões sobre quais seriam as melhores ferramentas para facilitar e incrementar as estratégias educativas na EAD. A interação entre os atores pedagógicos, docentes e estudantes, ainda representa um desafio para o desenvolvimento de tecnologias de informação e comunicação. A diversificação dos recursos, da flexibilidade e do investimento financeiro da modalidade gera uma demanda de aprendizes com exigências pontuais, essencialmente pensadas para suprir as suas necessidades reais de formação. Este contexto gera um repto constante para o planejamento didático dos conteúdos a serem abordados nos cursos de EAD. Na busca 
do conhecimento ele precisa pensar em meios que melhor the servirão para que o conteúdo aprendido seja levado para sua vida tendo de fato uma aprendizagem significativa, porque afinal só aprende-se realmente quando há significado para o objeto de estudo. (SILVA; RIBAS; KNAUT, 2014, p. 7). Em vista disso, é imperioso que a didática hoje seja amplamente repensada para atingir o grau de satisfação de um estudante consciente de suas metas, por meio de indicativos motivacionais adequados, sempre respeitando o ritmo de aprendizagem do mesmo.

\section{MODELOS DE EDUCAÇÃO A DISTÂNCIA}

Notoriamente associada ao Ensino Superior na atualidade, a Educação a Distância se mostra cada vez mais versátil, adaptando-se às imposições mercadológicas do mundo atual. É possível encontrar a modalidade em todas as áreas de conhecimento, promovendo a formação e a atualização do profissional ou ator social, gerando-lhe um perfil autônomo capaz de fazer frente à competitividade nos diversos setores de atuação. Mendonça (2016) aponta os principais modelos de Educação a Distância da atualidade:

1) Cursos livres: são treinamentos que podem ser sobre qualquer assunto e não são regulamentados por nenhum órgão do governo ou lei. Podem ser de aprimoramento pessoal ou profissional. Cursos de maquiagem, fotografia e idiomas são exemplos dessa categoria; 2) Cursos preparatórios: preparam o aluno para uma conquista ou um alcance de objetivo determinado. Cursos para concursos e processos seletivos para vagas públicas e cursos para exames como o da OAB (Conselho Federal da Ordem dos Advogados do Brasil) se encaixam nesse modelo; 3)Cursos técnicos e profissionalizantes: Técnicos: cursos com o objetivo de formar indivíduos para integrar o mercado de trabalho. Esses cursos requerem o cumprimento de determinados prérequisitos como forma de aprovação e elegibilidade frente ao Ministério da Educação. Profissionalizantes: similares aos cursos técnicos, têm como foco a capacitação profissional e não possuem pré-requisitos frente a órgãos governamentais. Se pode citar nesse tipo de curso, o Instituto Universal Brasileiro; 4)Cursos de graduação, pósgraduação e extensão. Graduação e Pós- Graduação: voltados para o nível superior, necessitam ser credenciados pelo MEC para funcionar, fator este que oferece ao estudante à garantia de qualidade de ensino. Extensão: espécie de especialização, objetivando o enriquecimento do currículo de profissionais graduandos a aprofundarem seus conhecimentos sobre determinado assunto ou tema adquiridos na graduação; 5)Cursos corporativos: de tendência e promoção das organizações, os cursos corporativos têm como objetivo treinar e capacitar colaboradores a alcançarem objetivos dentro de suas empresas, aumentando assim o engajamento do colaborador. As 
Universidades Corporativas são o maior expoente deste modelo; 6) Cursos de Mestrado e Doutorado: modelo mais recente de aplicação da EAD. O MEC homologou o Parecer $\mathrm{n}$ ? 462/2017 CNE/CES do Conselho Nacional de Educação outorgando novas regras e permitindo que os cursos de pós-graduação stricto sensu possa ser realizado à distância, considerando o processo de expansão da educação e o desenvolvimento do país. Em síntese, a Educação a Distância acompanha a evolução da sociedade, que hoje busca em seus indivíduos a proatividade, a consciência de sustentabilidade, a autonomia e a performance para que continue se desenvolvendo. A modalidade deve atuar como um multiplicador de conhecimento em diferentes perfis demográficos e econômicos.

\section{TENDÊNCIAS TECNOLÓGICAS E DIDÁTICAS NA EDUCAÇÃO A DISTÂNCIA}

Dado este cenário de variadas possibilidades e de inovações constantes e exponenciais, a Educação a Distância empenha-se em atualizar suas funcionalidades e recursos para fomentar o consumo de conteúdos, facilitando a sua absorção, levando em consideração a realidade desse novo aluno que é mais dinâmico e interativo. Estas atualizações pressupõem uma profunda análise do consumidor moderno da educação que possui acesso altamente oportunizado a smartphones, tablets, computadores, e que dispõe de tempo limitado para se dedicar aos estudos. Claro (2017) sustenta que a personalização do ensino é uma grande preocupação para os profissionais que estão compreendidos no mundo da educação, pois a concepção de personalizar está além da criação de um modelo que funciona para todos, mas sim da elaboração de um formato original que atenda às necessidades de todos os alunos. Alberton e Stolfi (2017), Argento (2017), Cooper (2017) e Pontes (2017) elencam as tendências tecnológicas e didáticas para a Educação a Distância, como sendo as seguintes: Microlearning, Mobile Learning, Gamificação, Learning Analytics, Realidade Virtual, Digital Storytelling, Blended Learning, Flipped Classroom e Social Learning. Algumas destas linhas de recursos não são exatamente recentes, no entanto seguem vigentes e cada vez mais fortes na educação em todos os níveis.

4.1 MICROLEARNING: se refere à administração de uma ferramenta de aprendizagem com um curto período de duração e com foco em um objetivo pontual. A aprendizagem acontece em passos menores, em geral por meio de materiais elaborados para serem utilizados entre 2 a 5 minutos, como podcasts, vídeos, artigos e slideshows. Buchem e Hamelmann (2010) sustentam que a microlearning facilita a aprendizagem, uma vez que atividades curtas podem ser facilmente integradas ao dia a dia. Pequenos passos de aprendizagem com parcelas menores de informação podem ser usados para aprender sob demanda. Desta forma, a microlearning permite que os indivíduos permaneçam 
atualizados, em consonância com uma economia na qual o conhecimento é um ativo, e oferece uma alternativa viável aos modelos mais formalizados e longos de aprendizagem, como cursos de sala de aula ou treinamentos na web. $O$ avanço do microlearning se dá de forma mais significativa no mundo corporativo, pois as empresas necessitam capacitar seus colaboradores em um espaço menor de tempo e a custos menores.

4.2 MOBILE LEARNING: Mobile learning, M-learning ou Aprendizagem com Mobilidade é uma modalidade de ensino que pode ser entendida como a integração dos dispositivos móveis com acesso à Internet no processo de aprendizagem, como smartphones, tablets e notebooks. Este modelo de aprendizagem na EAD apresenta grande aceitação por parte dos usuários, pela familiaridade que estes têm com os dispositivos móveis, em especial, "o telefone inteligente". Sendo assim, se pode afirmar que a mobile learning: [...] "torna possível o acesso, em tempo real, pelos chamados espaços virtuais, ao conhecimento sistematizado, ampliando-se $o$ ato educativo para além das salas de aulas, tornando o processo de ensino aprendizagem algo mais interativo, centrado no indivíduo-aprendiz, de caráter colaborativo" [...]. (SILVA; OLIVEIRA; BOLFE, 2013, p. 64). A Educação a Distância encontra na aprendizagem com mobilidade um aliado forte, posto que as instituições e organizações não necessitam realizar investimentos, pois os smartphones fazem parte do cotidiano de um grande montante da população de usuários de cursos.

4.3 GAMIFICAÇÃO: ou ludificação, do inglês "gamification", é o uso de mecânicas e dinâmicas de jogos que visam promover o engajamento do estudante a alcançar os seus objetivos. $O$ estudante se sente instigado a cumprir desafios e missões, projetados com base na proposta e no conteúdo educativo de seu curso ou treinamento. "Alguns sistemas gamificados podem ser baseados em premiações de acordo com rankings, pontuação, medalhas, desafios, missões, conquistas, entre outros; sendo estas características básicas de um sistema gamificado." (RICHARD, 2016, p. 32). É uma técnica amplamente utilizada, desde as escolas até o ambiente corporativo, já que se apresenta como uma resposta ao desinteresse, e consequentemente, à evasão comum aos cursos tradicionais.

4.4 LEARNING ANALYTICS: ou a análise da aprendizagem por meio da tecnologia, é um recurso que permite acessar os dados da interação do estudante com o Ambiente Virtual de Aprendizagem (AVA) e tratar, verificar e relacionar as informações obtidas. Por esse processo é possível descobrir o número de vezes que o aluno acessou o seu AVA, em quais exercícios apresentou mais dificuldade, a sua evolução no conteúdo, as ferramentas e recursos que mais utilizou, etc. As possibilidades são inúmeras e todas 
servem de base para a tomada de decisão mais assertivas de educadores e profissionais de tecnologia da informação (TI) para a elaboração de metodologias e abordagens que atendam às necessidades do aprendente. Apresenta-se como uma função de representar os dados e informações dos alunos que estão mais afastados da curva de aprendizagem no decorrer do percurso do curso para os professores tomarem as decisões. Também auxilia a avaliação dos planos de curso, currículos e programas institucionais. (ALMEIDA; BRENNAND, 2015 p. 14). Os dados são coletados e processados por meio de uma técnica composta de etapas, a Knowledge-Discoveryin Databases, conhecida como a descoberta de conhecimento em base de dados (DCBD). "O DCBD tem seus conceitos e processos para a utilização de bases de dados em processos de tomada de decisão modificando, através de processamentos contínuos, dados brutos em informações relevantes e conhecimento útil.” (DIAS, 2017, p. 4).

4.5 REALIDADE VIRTUAL: recurso tecnológico de criar um ambiente que simula a sensação da realidade de forma virtual. Oferece ao estudante uma aprendizagem mais estimulante, pois por intermédio de determinados dispositivos, ele pode ser inserido em um cenário artificial em 3D (três dimensões) que simula a realidade e irá interagir sensorialmente com esta experiência. A realidade virtual permite o envolvimento do aprendente em uma simulação pertinente ao conteúdo de seus estudos, o que facilita o entendimento, a memorização e a compreensão. Santos (2017) aponta algumas das vantagens do uso da realidade virtual, como por exemplo, a visualização de imagens de alta qualidade que promove o "encantamento" do estudante. Esse recurso aumenta o interesse do aluno, que prefere assistir algo que ler. A realidade virtual aumenta o engajamento produtivo e faculta a integração e a colaboração entre alunos e docentes. O estudante pode acessar um ambiente de realidade virtual por meio de dispositivos como capacete de visualização, luvas, o próprio corpo (gestos e comandos de voz), óculos, ou até mesmo dispositivos mais comuns e de custo menos elevado como mouse, teclado e monitor de vídeo.

4.6 DIGITAL STORYTELLING: Hack e Guedes (2013, p. 13) afirmam que [...] "o uso de parábolas, histórias e casos no processo de aprendizagem de adultos é antigo. Isso porque histórias oferecem uma ferramenta poderosa para promover a aprendizagem e o engajamento." Contar histórias é um modo de comunicar-se, usado há milênios para ensinar os mais jovens, entreter, transmitir elementos culturais, sociais e éticos. Se denonima Digital Storytelling, que pode ser traduzida como "narrativa digital', à técnica de contar histórias por meio de recursos audiovisuais digitais, oferecendo ao aluno uma abordagem instigante de aprendizagem. Conforme Wang e Zhan (2010, p.78), "digital storytelling pode ser uma ação instrutiva, persuasiva, histórica e reflexiva." $O$ desenvolvimento do material deve ser pensado para que ele realmente leve o conteúdo 
educacional ao aluno de uma maneira lúdica e colaborativa. O estudante se identifica com a história, se esta for bem contada, com seus conflitos, dramas e emoções. Dessa forma, por ser algo prazeroso, o aluno tende a reter informações com mais eficácia.

4.7 BLENDED LEARNING: ou ensino híbrido, é um modelo de educação que mescla atividades online e presenciais. Também é conhecido como semipresencial e visa proporcionar ao estudante duas diferentes formas de estudar um mesmo conceito. Durante seu momento de estudo a distância, o aluno tem a flexibilidade de acessar os temas a serem explorados no tempo e local que Ihe forem convenientes e, além disso, pode refletir e preparar-se para o momento presencial com o professor, no qual poderá expor suas dúvidas remanescentes (RODRIGUES, 2010). Que não se entenda que este processo minimize o trabalho do docente, pois este, ademais de ser o detentor do conhecimento, deverá estar preparado para ser um facilitador de aprendizagem, que converte a sala de aula em um ambiente dialógico e interativo, opondo-se ao velho modelo de educação no qual o estudante tinha um papel passivo. Flipped Classroom, também conhecida como Sala de Aula Invertida, é uma das propostas de ensino híbrido. O aluno recebe previamente o material relacionado ao assunto a ser estudado, por meio de vídeo aulas, livros impressos, acesso a bibliotecas virtuais, objetos de aprendizagem e interage em recursos do Ambiente Virtual de Aprendizagem (AVA), como por exemplo, fóruns e chats. $O$ estudante realiza o auto estudo, para então, em sala, colocar seus conhecimentos em prática, realizando atividades de discussão em grupo, de resolução de problemas, participação em palestras, entre outros. Valente (2014, p. 85) enfatiza que "a combinação do que ocorre on-line com o que ocorre em sala de aula presencialmente pode ser muito rica e beneficiar a aprendizagem dos alunos sob todos os aspectos." Nesta abordagem pedagógica, o estudante é estimulado a se preparar para a aula e se auto avalia, identificando quais pontos do conteúdo necessitam de mais esclarecimento no momento presencial.

4.8 SOCIAL LEARNING: Social Learning pode ser descrita como uma experiência de aprendizado em redes de relacionamento, se utilizando de materiais online que possam ser compartilhados por meio de postagens em blogs e em redes sociais, fóruns de discussão, reuniões online, grupos de Whatsapp, etc. O foco dessa abordagem reside na troca de ideias e colaboração que acontece entre as pessoas que estejam fazendo 0 mesmo curso. Esta tendência tem sido muito popular em treinamentos corporativos, para ampliar os conhecimentos por meio da interação dos colaboradores que os realizam. Porciúncula, et al (2012, p. 13) considera que: No social learning, a troca de conhecimento ganha destaque, pois essa abordagem é efetiva para apoiar colaboradores a terem alto desempenho. Isso acontece porque a colaboração estimula a aprendizagem entre pares, seja em um projeto em comunidades de prática ou em 
ambientes de trabalho. Essa é a base do social learning: a troca, a colaboração. A construção do conhecimento por meio de redes explica a relevância do social learning no ambiente de trabalho. O desejo de compartilhar é algo inerente ao ser humano, e as mídias sociais ancoradas na tecnologia avançada só fizeram impulsionar o processo de comunicação entre pessoas que tenham um interesse em comum, incluídos aqui, os colaboradores de uma mesma organização ou estudantes de uma mesma instituição.

\section{METODOLOGIA}

A metodologia para o desenvolvimento deste trabalho define-se como descritiva e segundo Prodanov e Freitas (2013) ocorre quando o pesquisador apenas registra, analisa e ordena dados como o intuito de descrever os fatos sem interferir neles. A pesquisa foi realizada por meio de levantamento bibliográfico realizado em livros, artigos acadêmicos e fontes eletrônicas nacionais e internacionais para elucidar os principais modelos de ensino na educação a distância e os recursos da tecnologia e da didática nesta modalidade.

\section{CONSIDERAÇÕES FINAIS}

Este trabalho teve como objetivo a exposição das principais tendências tecnológicas e didáticas na modalidade de Educação a Distância, de maneira a contextualizar e informar os envolvidos na elaboração e implementação de abordagens de aprendizado na EAD. Existem vários modelos de educação a distância para diferentes públicos: cursos livres, cursos preparatórios, cursos técnicos, cursos profissionalizantes, cursos de graduação e pós-graduação, cursos de extensão, cursos corporativos e cursos de Mestrado e Doutorado. Estes modelos são influenciados pelo ritmo de incremento dos recursos tecnológicos e necessitam adaptar-se à realidade de um estudante que já não é mais passivo, como outrora, e que detém o controle da evolução de seu aprendizado. Com base no estudo da arte, as tendências tecnólogicas e didáticas geradas no recente cenário da EAD são as seguintes: Microlearning, Mobile Learning, Gamificação, Learning Analytics, Realidade Virtual, Digital Storytelling, Blended Learning, Flipped Classroom e Social Learning. Não são exatamente novidades no mundo da educação, mas seguem como fortes abordagens nesta área. Os resultados deste estudo teórico nos levam à primordialidade de estudos e pesquisas mais específicas sobre cada manifestação destas tendências no sentido de produzir um refinamento nos conteúdos e recursos pedagógicos, levando-se em consideração a existência de aprendentes dessa nova era tecnológica, cada vez exigentes.

\section{REFERÊNCIAS}


ALBERTON, M. M.; STOLFI, A. M. Os Desafios Pedagógicos Na Educação A Distância. Revista Maiêutica, Indaial, v. 5, n. 01, p. 89-98, 2017.

ALMEIDA, L. H. G. de; BRENNAND, E.G. de G. Learning Analytics em ambiente virtual de aprendizagem Moodle: um estudo de caso em componentes curriculares para cursos semipresenciais. Gestão \& Aprendizagem, v. 4, n. 2, 2015.

ARGENTO, H. Conheça as 12 tendências tecnológicas mais importantes na educação. Professor do Futuro, 2017. Disponível em: . Acesso em 18 fev. 2018.

BUCHEM, I.; HAMELMANN, H. Microlearning: a strategy for ongoing professional development. ELearning Papers, elearningeuropa.info, n. 21, p. 1-15, 2010.

CLARO, M. 10 tendências de personalização do ensino em 2017. Moodle Livre. Disponível em: . Acesso em 18 fev. 2018.

COOPER, S. 7 Trends to Expect from Social Learning In 2017. ELearning Industry, 2017. Disponível em: < https://elearningindustry.com/7-trends-expect-social-learningin-2017>. Acesso em: 26 fev. 2018.

DIAS, R. S. Caracterização do Learning Analytics na Educação a Distância. Seminário de Pesquisa e Inovação Tecnológica, 2017. Disponível em: < http://editora.iftm.edu.br/index.php/sepit/article/view/312/145>. Acesso em: 04 mar. 2018.

HACK, J. R.; GUEDES, O. Digital Storytelling, Educação Superior e Literacia Digital. Roteiro, Joaçaba, v. 38, n. 1, p. 9-32, jan./jun. 2013.

LITTO, M. F.; FORMIGA, M. M. M. (orgs.). A Educação a Distância: o estado da arte. São Paulo: Pearson Education do Brasil, 2009.

MENDONÇA, B. 7 modelos de EAD para explorar o mercado de educação. 2016. Disponível em: < https://www.edools.com/modelos-de-ead/> Acesso em: 17 fev. 2018.

PARECER CNE/CES № 462/2017.

PONTES, E. Tendências de educação corporativa: separamos 15 nessa lista. 2017. Disponível em: < https://eadbox.com/tendencias-de-educacao-corporativa/> Acesso em: 18 fev. 2018. 
PORCIÚNCULA, E. F. S. et al. Formação docente em EAD ancorada no novo social learning: da teoria à praxis no FGV Online. Revista FGV Online, Rio de Janeiro, v. 2, n. 2, p. 58-79, abr. 2012.

PRODANOV, Cleber Cristiano; FREITAS, Ernani Cesar de. Metodologia do trabalho científico: métodos e técnicas de pesquisa e do trabalho acadêmico. 2. ed. Novo Hamburgo/RS: Feevale, 2013. Disponível em: http://migre. me/eqVxf. Acesso em: 06 jul. 2018.

RICHARD, T. C. Aplicação de gamificação e microlearning: um aprimoramento na plataforma de gestão de aprendizagem da IMAGINARIUM. Florianópolis, 2016, 103 p. Trabalho de conclusão de curso (graduação em Administração) - Universidade Federal de Santa Catarina, Centro Sócio Econômico.

RODRIGUES, L. A. Uma Nova Proposta para o Conceito de Blended Learning. Interfaces da Educação. Paranaíba, v. 1, n. 3 p.5-22. 2010.

SANTOS, B.. Benefícios do Uso da Realidade Virtual na Educação à Distância. 2017. Disponívelem:<http://www.flexinterativa.com.br/blogflex/benef\%C3\%ADcios-do-uso-darealidade-virtual-na-educa\%C3\%A7\%C3\%A30-\%C3\%A0-dist\%C3\%A2ncia>. Acesso em: 06 mar. 2018.

SILVA, J. M. da; RIBAS, C. C. C.; KNAUT, M.S. J. A Relação Professor/Aluno na Ead e a Promoção da Aprendizagem Significativa. Ensaios pedagógicos - Revista Eletrônica do Curso de Pedagogia das Faculdades OPET. OPET, n.8, 2014.

SILVA, L. F. da; OLIVEIRA Eder Diego de; BOLFE, Marcelo Bolfe. Mobile Learning: Aprendendizagem com Mobilidade. Colloquium Exactarum, vol. 5, n. Especial, Jul-Dez, 2013, p. 59-65.

VALENTE, J. A.. Blended learning e as mudanças no ensino superior: a proposta da sala de aula invertida. Educar em Revista, Curitiba, Brasil, Edição Especial n. 4/2014, p. 79-97. Editora UFPR.

WANG, S.; ZHAN, H.. Enhancing Teachingand Learning with Digital Storytelling. International Journal of Information and Communication Technology Education, 6(2), 76-87, April-June 2010. 